\title{
Persistence and adherence in multiple sclerosis patients starting glatiramer acetate treatment: assessment of relationship with care received from multiple disciplines
}

\author{
This article was published in the following Dove Press journal: \\ Patient Preference and Adherence \\ 24 May 2016 \\ Number of times this article has been viewed
}

\author{
Peter Joseph Jongen ${ }^{1,2}$ \\ Wim A Lemmens ${ }^{3}$ \\ Raymond Hupperts ${ }^{4}$ \\ Erwin LJ Hoogervorst ${ }^{5}$ \\ Hans M Schrijver ${ }^{6}$ \\ Astrid Slettenaar ${ }^{7}$ \\ Els L de Schryver ${ }^{8}$ \\ Jan Boringa? \\ Esther van Noort ${ }^{10}$ \\ Rogier Donders ${ }^{3}$ \\ 'Department of Community and \\ Occupational Medicine, University \\ Medical Centre Groningen, University \\ Groningen, Groningen, ${ }^{2}$ MS4 Research \\ Institute, ${ }^{3}$ Department for Health \\ Evidence, Radboud university medical \\ center, Nijmegen, ${ }^{4}$ Department of \\ Neurology, Zuijderland Medisch \\ Centrum Sittard, Sittard, ${ }^{5}$ Department \\ of Neurology, St Antonius Hospital, \\ Nieuwegein, ${ }^{6}$ Department of Neurology, \\ Multiple Sclerosis Centre, Westfries \\ Gasthuis, Hoorn, ${ }^{7}$ Department of \\ Neurology, Medisch Spectrum Twente, \\ Enschede, ${ }^{8}$ Department of Neurology, \\ Alrijne Ziekenhuis, Leiderdorp, \\ 'Department of Neurology, Meander \\ Medisch Centrum, Amersfoort, \\ ${ }^{10}$ Curavista BV, Geertruidenberg, the \\ Netherlands
}

Correspondence: Peter Joseph Jongen Department of Community and Occupational Medicine, University Medical Centre Groningen, University Groningen,

Antonius Deusinglaan I, 9713 AV,

Groningen, the Netherlands

Tel +31 243239146

Email p.j.h.jongen@rug.nl

\begin{abstract}
Background: In multiple sclerosis patients, the persistence of, and adherence to, disease-modifying treatment are often insufficient. The degree of persistence and adherence may relate to the care received from various disciplines.

Methods: In an observational study of 203 patients treated with glatiramer acetate $20 \mathrm{mg}$ subcutaneous daily, we assess the persistence and adherence in relation to the amount of care received in various disciplines. The frequencies and durations of care per discipline were reported by patients online, as were missed doses and eventual treatment discontinuation. The associations between the care provided by neurologists, nurses, psychologists, pharmacists, and rehabilitative doctors and persistence and adherence were the primary outcomes; the associations between care received from general practitioners, occupational therapists, physiotherapists, social workers, dieticians, home caregivers, informal caregivers, other medical specialists, and other caregivers and persistence and adherence were secondary outcomes.
\end{abstract}

Results: It was found that the 12 -month persistence rate was $62 \%$ and that $85 \%$ of the persistent patients were $95 \%$ adherent (missed $<5 \%$ of doses). Patients who discontinued treatment in the fourth quarter $(\mathrm{Q})$ had received less-frequent and shorter psychological care in $\mathrm{Q} 3$ than persistent patients $(P=0.0018$ and $P=0.0022)$. Adherent patients had received more frequent home care and informal care than nonadherent patients $(P=0.0074$ and $P=0.0198)$, as well as longer home care and informal care $(P=0.0074$ and $P=0.0318)$. Associations between care in other disciplines and persistence or adherence were not observed. As to the relationship between adherence and persistence, nonadherence in Q2 was related to discontinuation after Q2 $(P=0.0001)$.

Conclusion: We obtained no evidence that, in multiple sclerosis patients, persistence of and adherence to disease-modifying treatment are associated with the amount of neurological, nursing, pharmaceutical, or rehabilitative care. However, findings suggest that the treatment of psychological problems in Q3 may relate to persistence and that home care and informal care may relate to adherence.

Keywords: home care, informal care, nursing, pharmaceutical, rehabilitative, psychological

\section{Introduction}

Multiple sclerosis (MS) is a chronic inflammatory, demyelinating, and degenerative disease of the central nervous system, for which no definite cure is available. In about the first 20 years of the disease, most patients show a relapsing-remitting (RR) course, during which incomplete remissions often cause stepwise increases in disability. Glatiramer acetate (GA), interferon-beta (INF $\beta$ )-1a, and INF $\beta$-1b are first-line, parenterally 
administered, disease-modifying drugs (DMDs) for RRMS that reduce relapses and disability progression. ${ }^{1}$ Postauthorization studies showed that treatment with injectable DMDs is associated with an increase in health-related quality of life ${ }^{2,3}$ and that, in the long term, these drugs may indeed prevent or delay an increase in disability and a conversion to secondary progressive MS. ${ }^{4}$

In general, medication for chronic illness is only taken by $50 \%-60 \%$ of the patients as prescribed. ${ }^{5,6}$ Not taking medication as prescribed includes the following two different patient behaviors: premature treatment discontinuation (nonpersistence) and missing doses (nonadherence). ${ }^{6}$ There is evidence that, in RRMS, high DMD exposure is associated with better clinical outcomes than low DMD exposure, ${ }^{7,8}$ which means that a continuous use and a minimum of missed doses provide the greatest clinical benefit. ${ }^{9,10}$

Discontinuation of disease-modifying treatment mostly occurs in the first 12 months. ${ }^{9-11}$ At 4 months, up to $11 \%$ of RRMS patients treated with injectable DMDs have discontinued treatment, ${ }^{12}$ and after 6 months, figures vary from $9 \%$ to $27 \% .{ }^{13}$ However, discontinuation rates in MS-specialized academic centers were only $1.7 \%$ after 6 months and $8 \%$ after 2 years, ${ }^{14}$ suggesting that persistence may relate to qualitative or quantitative aspects of care; MS-specialized centers often provide care from multiple disciplines, whereas care may be more limited in hospitals without a special interest in MS. Data on the percentages of missed DMD doses in RRMS vary. In MS patients with two or more DMD dispensings, the mean medication possession ratio was found to be $68 \%$ for a 2 -year period. ${ }^{11}$ In contrast, sc INF $\beta$-1a-treated patients, where an electronic autoinjector is used with real-time recording of injections, showed a mean adherence of $95 \%$ over a period of 1.5 (SD 1.0) years. ${ }^{12}$

According to the World Health Organization 2003 report $^{6}$ and a recent Cochrane Review, 18 multidisciplinary interventions may improve both adherence and persistence. Therefore, detailed knowledge on which care disciplines and what amounts of care are associated with persistence and adherence could help to optimize the multidisciplinary care in RRMS patients starting a DMD and could also guide the development of persistence- and adherence-promoting measures.

In view of the details described we decided to assess in RRMS patients who started parenteral DMD treatment, the relationship between multiple disciplines of care, and persistence and adherence. As INF $\beta$ and GA have clearly different side effect profiles and injection frequencies and as both these aspects are likely to influence persistence and adherence, we chose to study patients treated with one type of DMD, thus guaranteeing a homogeneous study population. Because pilot data on discontinuation and risk factors were available for patients treated with GA $20 \mathrm{mg}$ subcutaneous (sc) daily in the Netherlands, ${ }^{13}$ it was decided to study patients starting treatment with GA $20 \mathrm{mg}$ sc daily. We hypothesized that early discontinuation or missing doses were related to less-frequent neurological, nursing, psychological, pharmaceutical, or rehabilitative care contacts or shorter care duration in one or more of these disciplines.

\section{Materials and methods Study design}

The methods and design of the study have been described in detail. ${ }^{13}$ In brief, the Correlative Analysis of Adherence in RRMS (CAIR) study was an investigator-initiated, prospective, web-based, patient-centered, observational study in the Netherlands. The primary objective was to investigate whether persistence of and adherence to daily treatment with GA $20 \mathrm{mg}$ sc daily was associated with the quantity of care received from certain predetermined disciplines. The study duration was 12 months (Nederlands Trial Register code: TC2432). GA was prescribed by neurologists as per regular care and dispensed as a commercial drug by general pharmacies (Copaxone ${ }^{\circledR}$ ). GA was administered according to the instructions in the package leaflet. The recruitment period was from July 2009 to July 2011. The inclusion criteria for participation were as follows: 1) indication for GA treatment, 2) being relapse free and having stable symptoms for at least 30 days, 3) willing and able to comply with the protocol, 4) having given informed consent, and 5) having access to the Internet. The exclusion criteria were as follows: 1) contraindication for GA as defined in the "Summary of product characteristics"15 text, 2) hypersensitivity to GA or mannitol, 3) symptoms suggestive of a relapse, 4) pregnancy or lactation, and 5) the time interval between the first GA injection and baseline assessment being $>4$ weeks.

\section{Ethical aspects}

The protocol was submitted to the Independent Review Board, an approved ethical committee residing in Amsterdam, the Netherlands. The committee concluded that, because of the observational design of the study, a review by an ethical committee was not required, as the study did not qualify for being tested according to the Dutch Medical Research involving Human Subjects Act of $1999 .{ }^{14}$ The study was performed in agreement with the Declaration of Helsinki (Ethical Principles for Medical Research Involving Human Subjects Version 2013; 64th World Medical Association 
General Assembly, Fortaleza, Brazil, October 2013) (www. wma.net) and the Wet medisch-wetenschappelijk onderzoek met mensen [Dutch Medical Research involving Human Subjects Act] (www.wetten.overheid.nl/BWBR0009408). Patients were informed that they had the right to discontinue their participation or withdraw their consent at any time and were not obliged to state their reasons. They were informed that study discontinuation would not interfere with the care. The completion of the questionnaire about the care took 15-20 minutes every 2 weeks, and the completion of the questionnaire about missed doses and treatment discontinuation took $<5$ minutes at twelve time points.

\section{Technical aspects}

The study was a modular application on the Curavista eHealth platform, built on an Oracle database with JAVA scripting, XML applets, and AJAX protocols. Data processing was 256 bits encrypted with VPN tunneling. The databases were physically and software secured in a dedicated data center in the Netherlands. The database of the study was compliant with European Union (EU) regulations on data storage and activation for medical purposes. There were four separated databases: one with personal identifiers (name, address, and identification number), one with study records (answers to the questions and identification number), one with the social security number, and one with the key. Only after logging on, the data were presented as a whole on the screen (encrypted key).

\section{Data acquisition}

Data were acquired via the study website (www.cairstudie.nl). Patients logged on with a code provided by the study help desk and chose a username and a password. When online, they went through web pages containing the electronic case record forms (eCRFs). Patients were informed by email that an assessment was due and that the corresponding forms had been made available for completion. eCRFs were to be completed within 1 week. Completion could take as many sessions as needed, as answers were saved automatically. After confirmation by the patient, the eCRF was automatically sent to the study center. Incomplete eCRFs were returned. In the case of an eCRF not being completed within 1 week, the help desk reminded the patient by telephone.

\section{Outcomes and assessment schedule}

\section{Persistence and adherence}

At 12 time points - at 3 months, 6 months, 9 months, and 12 months after the start of treatment and at eight random time points unknown to patients, neurologists, and nurses - the following data were reported by the patients: the number of missed doses in the preceding 14 days, the eventual discontinuation of GA, and the date of discontinuation (if applicable). Thus, patient-reported data were obtained covering 20 weeks of the 52-week study period. The distribution of the assessments over the year was as follows: at 4 weeks, 10 weeks, 12 weeks, 16 weeks, 20 weeks, 26 weeks, 32 weeks, 34 weeks, 38 weeks, 44 weeks, 48 weeks, and 52 weeks after the start of treatment.

\section{Multiple disciplines of care}

Care provided by the following disciplines was assessed: neurologist, nurse, psychologist, pharmacist, rehabilitation doctor, general practitioner, other medical specialists, occupational therapist, physiotherapist, social worker, dietician, home caregivers, informal caregivers, and other caregivers. Care was defined as visits to outpatient departments, hospital visits, contacts by telephone, contacts via the Internet, health-promoting activities that are coached or counseled by caregivers (eg, medical fitness), care received at home, or any other activity considered by the patient as such. Care received in the preceding 14 days was reported by patients at baseline and every 2 weeks thereafter up to week 52. For every discipline from which care was received, the number of care sessions and the time per care session (in minutes, by approximation) were documented. Thus, all care received during the 12-month study period was assessed.

\section{Disease characteristics}

At baseline, the treating neurologist or nurse provided the following data: the course of the disease, the duration of the disease, previous DMD treatment, and the number of relapses in the last 12 months and 24 months.

\section{Statistical analyses}

Based on the patient-reported data, the percentage of missed doses was calculated. Against the background of reports in the literature, we first explored the number of nonadherent patients, using $85 \%, 90 \%, 95 \%$, and $99 \%$ of the prescribed doses taken as cutoff points. The cutoff point that enabled the most meaningful analyses was used in the subsequent analyses. Based on the 2-weekly patient reports, we calculated the care frequency (number of contacts) and the care duration (minutes) over a 3-month (quarter [Q]) and the 12-month study period for various disciplines. Comparisons were made between adherent and nonadherent patients and between persistent and nonpersistent patients using a twosided $t$-test (continuous variables) and a two-sided chi-square 
test (dichotomous variables). The analyses focused on the neurological, nursing, psychological, pharmaceutical, and rehabilitative care disciplines, considering a $P$-value of $<0.05$ as significant. The analyses of the care provided by the general practitioner, occupational therapist, physiotherapist, social worker, dietician, home caregivers, informal caregivers, other medical specialists, and other caregivers were secondary and explorative. To investigate whether treatment discontinuation was preceded by a relative lack of care, we related the number of neurological, nursing, psychological, pharmaceutical, and rehabilitative care contacts and durations in a given quarter to discontinuation after that. Similar analyses were performed for the other care disciplines in an explorative way. To optimally identify care aspects that were specifically related to adherence, we analyzed the relationship between care and adherence in patients who were 12-month persistent.

\section{Results}

\section{Demographic and disease characteristics}

A total of 203 patients were included in the study. Three patients failed to complete a single questionnaire and were, therefore, removed from the data set. Of the resulting 200 analyzable patients, 157 (78.5\%) patients were females and 43 (21.5\%) patients were males (female-to-male ratio 3.65:1). The demographic and disease characteristics are presented in Table 1.

\section{Persistence}

One hundred twenty-four (62.00\%) patients continued treatment for at least 12 months, whereas 76 (38.00\%) patients stopped treatment before the end of the study, yielding a 12 -month persistence rate of $62 \%$. The mean time at

Table I Demographic and disease characteristics of patients $(\mathrm{N}=200)$

\begin{tabular}{|c|c|}
\hline Characteristic & $\begin{array}{l}\text { Mean, unless indicated } \\
\text { otherwise }\end{array}$ \\
\hline Female-to-male ratio & $3.65: 1$ \\
\hline Age (years) & $\begin{array}{l}39.66 \text { (SD 9.75, minimum } 19 \text {, } \\
\text { maximum } 62 \text { ) }\end{array}$ \\
\hline $\begin{array}{l}\text { Disease duration (years) } \\
(\mathrm{N}=107)\end{array}$ & $\begin{array}{l}4.48 \text { (SD } 4.96, \text { minimum } 0 \text {, } \\
\text { maximum } 18 \text { ) }\end{array}$ \\
\hline $\begin{array}{l}\text { Relapsing course } \\
(\mathrm{N}=104 \text { out of } 1 / 2)\end{array}$ & $92.86 \%$ \\
\hline $\begin{array}{l}\text { Secondary progressive } \\
\text { course }(\mathrm{N}=10 \text { out of } \mathrm{III})\end{array}$ & $9.01 \%$ \\
\hline $\begin{array}{l}\text { Previous disease-modifying } \\
\text { treatment ( } N=40 \text { out of } 108)\end{array}$ & $37.04 \%$ \\
\hline $\begin{array}{l}\text { Relapses in previous } 12 \text { months } \\
(\mathrm{N}=|| 3)\end{array}$ & $\begin{array}{l}\text { I. } 22 \text { (SD 0.83, minimum } 0 \text {, } \\
\text { maximum } 3 \text { ) }\end{array}$ \\
\hline $\begin{array}{l}\text { Relapses in previous } 24 \text { months } \\
(\mathrm{N}=\mathrm{II0})\end{array}$ & $\begin{array}{l}\text { I.64 (SD I.05, minimum } 0 \text {, } \\
\text { maximum } 6 \text { ) }\end{array}$ \\
\hline
\end{tabular}

which treatment was discontinued was 6.4 months (SD 3.4, minimum 1.0, maximum 12.0). The female-to-male ratio did differ between persistent (4.17:1) and nonpersistent patients $(3: 1)$, in which female patients were more prone to continue treatment $(P=0.035)$. The age did not differ between persistent (mean 39.9, SD 9.8, minimum 19.0, maximum 62.0 years) and nonpersistent (mean 39.2, SD 9.6, minimum 20.0, maximum 58.0 years $)$ patients $(P=0.60)$. Fifty-four $(71.10 \%)$ of the 76 nonpersistent patients stated one or more reasons for their treatment discontinuation. Of a total of 62 reasons provided, 33 (53.23\%) were side effects, $12(19.40 \%)$ were lack of effectiveness, and 17 (27.42) were other reasons.

\section{Adherence}

In the persistent group $(\mathrm{N}=124)$, we explored the number of adherent vs nonadherent patients by using 15\%,10\%, 5\%, and $1 \%$ missed doses as cutoff points, resulting in $85 \%, 90 \%$, $95 \%$, and $99 \%$ adherence, respectively. Thus, of the persistent patients, 123 (99.19\%) were 85\% adherent, 115 (92.74\%) were $90 \%$ adherent, 105 (84.68\%) were 95\% adherent, and $59(47.58 \%)$ were $99 \%$ adherent. To maximize our chances to find statistically significant and clinically relevant differences between adherent and nonadherent patients, we chose $95 \%$ adherence as the cutoff point. Consequently, 105 (52\%) patients were both persistent and adherent.

\section{Relationship between adherence and persistence}

To investigate whether treatment discontinuation was preceded by nonadherence, we compared the adherence in Q1, Q2, and Q3 in patients who had discontinued treatment after Q1, Q2, and Q3, respectively, with the adherence in patients who had not discontinued in the corresponding quarters. Thus, we found an association between nonadherence in Q2 and discontinuation after Q2: nine (31.0\%) of 29 Q2 nonadherent patients discontinued treatment after Q2, whereas only eight (6.4\%) of $126 \mathrm{Q} 2$ adherent patients did so $(P=0.0001)$. The association between nonadherence in Q3 and discontinuation in Q4 failed to be statistically significant $(P=0.0899)$, whereas no difference was found in Q1 adherence between patients who had discontinued treatment after Q1 (adherent $\mathrm{N}=22$ and nonadherent $\mathrm{N}=3$ ) and those who had not discontinued after Q1 (adherent $\mathrm{N}=137$ and nonadherent $\mathrm{N}=18)(P=0.9554)$.

\section{Relationship between care and persistence}

To investigate whether treatment discontinuation was preceded by a relative lack of neurological, nursing, 
psychological, pharmaceutical, or rehabilitative care, we calculated the care frequencies and durations in the quarter preceding discontinuation $(\mathrm{Q} 1, \mathrm{Q} 2$, and Q3) in patients who had discontinued treatment in Q2 $(\mathrm{N}=25), \mathrm{Q} 3(\mathrm{~N}=17)$, and Q4 $(\mathrm{N}=14)$, respectively, and compared these with the data in patients who had not discontinued in the corresponding quarters (Q2 [N=154], Q3 [N=138], and Q4 [N=124], respectively). It was found that patients who discontinued treatment in Q4 had less-frequent (mean 0.07, SD 0.27, minimum 0, maximum 1) and shorter psychological care (mean 4.29, SD 16.04, minimum 0, maximum 60) in Q3 than persistent patients (mean 0.47, SD 1.11, minimum 0, maximum 6 and mean 28.23, SD 69.68, minimum 0, maximum 375, respectively) ( $P=0.0018$ and $P=0.0022$, respectively). No other differences were found (all $P>0.0467$ ).

To explore whether treatment discontinuation was preceded by less-frequent or shorter care given by the general practitioner, occupational therapist, physiotherapist, social worker, dietician, home caregivers, informal caregivers, other medical specialists, and other caregivers, we made similar analyses for these disciplines. No differences were found (all $P>0.05$ ), except that patients who discontinued in Q4 had received shorter care by other medical specialists than persistent patients (mean 7.14, SD 11.88, minimum 0, maximum 40 vs mean 46.90, SD 145.79, minimum 0 , maximum 900) $(P=0.0037)$.

\section{Relationship between care and adherence}

In order to investigate aspects of care specifically related to adherence, we analyzed the relationship between multiple care disciplines and adherence in the persistent patient group ( $\mathrm{N}=124)$. For neurological, nursing, psychological, pharmaceutical, and rehabilitative cares, we compared the care frequency (number of contacts) and the care duration (minutes) in the 12-month study period between adherent $(\mathrm{N}=105)$ and nonadherent $(\mathrm{N}=19)$ patients. No differences were found, neither in the care frequencies (all $P>0.2942$ ) nor in care durations (all $P>0.2570$ ) (Table 2). In addition, to explore the possibility that care given in a specific period, eg, in the first 3 months of treatment, was instrumental in bringing about adherence, we also made comparisons with respect to quarterly care data. No differences between adherent and nonadherent patients were found either (all $P>0.05$ ).

The explorative analysis pertaining to the frequencies and durations of care given by the general practitioner, occupational therapist, physiotherapist, social worker, dietician, home caregivers, informal caregivers, other medical specialists, and other caregivers suggested that adherent patients had received more frequent home care (mean 1.06, SD 3.97, minimum 0, maximum 24) and more frequent informal care (mean 1.47, SD 5.24, minimum 0, maximum 25) than nonadherent patients (mean 0.00, SD 0.00, minimum 0 , maximum 0 and mean 0.21 , SD 0.63 , minimum 0 , maximum 2 , respectively) ( $P=0.0074$ and $P=0.0198$, respectively). Similarly, the home care and informal care durations were longer in adherent (mean 211.90, SD 795.50, minimum 0, maximum 4,785 and mean 472.84, SD 2,126.78, minimum 0, maximum 15,275 , respectively) than in nonadherent patients (mean 0.00, SD 0.00, minimum 0, maximum 0 and mean 19.26, SD 82.52, minimum 0 , maximum 360 , respectively) ( $P=0.0074$ and $P=0.0318$, respectively). No other differences were found (all $P>0.05$ ) (Table 3 ).

Then, to further explore whether home care or informal care given in a specific period was related to adherence, we compared the quarterly care data. Whereas nonadherent patients $(\mathrm{N}=19)$ had received no home care (mentioned earlier), adherent patients reported quarterly home care in Q1, Q2, Q3, and Q4 (mean values 1.80, 1.80, 2.20, and

Table 2 Neurological, nursing, psychological, pharmaceutical, and rehabilitative care frequencies (number of contacts) and durations (minutes) in adherent vs nonadherent patients over the 12-month study period

\begin{tabular}{|c|c|c|c|c|c|c|c|c|c|}
\hline & \multicolumn{4}{|c|}{ Adherent patients $(\mathrm{N}=105)$} & \multicolumn{4}{|c|}{ Nonadherent patients $(\mathrm{N}=19)$} & \multirow{2}{*}{$\begin{array}{l}\text { Two-sided } \\
\text { t-test ( } P \text {-value) }\end{array}$} \\
\hline & Mean & SD & Minimum & Maximum & Mean & SD & Minimum & Maximum & \\
\hline \multicolumn{10}{|l|}{ Care frequency (n) } \\
\hline Neurologist & 3.38 & 2.25 & 0 & II & 3.26 & 2.56 & 0 & 12 & 0.8525 \\
\hline Nurse & 4.76 & 4.22 & 0 & 22 & 5.21 & 4.76 & 0 & 21 & 0.7040 \\
\hline Psychologist & 1.40 & 3.37 & 0 & 18 & 2.53 & 4.34 & 0 & 17 & 0.2942 \\
\hline Pharmacist & 2.37 & 4.05 & 0 & 17 & 2.05 & 2.86 & 0 & 13 & 0.6798 \\
\hline Rehabilitation & 1.24 & 2.14 & 0 & 9 & 1.68 & 2.43 & 0 & 6 & 0.4607 \\
\hline \multicolumn{10}{|c|}{ Care duration (minutes) } \\
\hline Neurologist & 68.97 & 59.15 & 0 & 280 & 95.26 & 87.60 & 15 & 350 & 0.2224 \\
\hline Nurse & 126.43 & 125.58 & 0 & 585 & 138.23 & $|84.0|$ & 0 & 835 & 0.7910 \\
\hline Psychologist & 86.86 & 228.63 & 0 & $\mathrm{I}, 525$ & 169.74 & 294.88 & 0 & $\mathrm{I}, \mathrm{I} 40$ & 0.2570 \\
\hline Pharmacist & 22.42 & 42.71 & 0 & 230 & 24.89 & 44.75 & 0 & 200 & 0.8250 \\
\hline Rehabilitation & 50.05 & 163.37 & 0 & $\mathrm{I}, 570$ & 40.79 & 52.16 & 0 & 140 & 0.6434 \\
\hline
\end{tabular}


Table 3 Frequencies (number of contacts) and durations (minutes) of care given by general practitioners, occupational therapists, physiotherapists, social workers, dieticians, home caregivers, informal caregivers, other medical specialists, and other caregivers in adherent vs nonadherent patients over the 12-month study period

\begin{tabular}{|c|c|c|c|c|c|c|c|c|c|}
\hline & \multicolumn{4}{|c|}{ Adherent patients $(\mathrm{N}=105)$} & \multicolumn{4}{|c|}{ Nonadherent patients $(\mathrm{N}=19)$} & \multirow{2}{*}{$\begin{array}{l}\text { Two-sided } \\
\text { t-test }(P \text {-value })\end{array}$} \\
\hline & Mean & SD & Minimum & Maximum & Mean & SD & Minimum & Maximum & \\
\hline \multicolumn{10}{|l|}{ Care frequency (n) } \\
\hline General practitioner & 2.52 & 3.01 & 0 & 12 & 2.58 & 2.67 & 0 & 9 & 0.9360 \\
\hline Physiotherapist & 8.88 & 9.28 & 0 & 26 & 9.68 & 9.76 & 0 & 25 & 0.7410 \\
\hline Occupation therapist & 1.58 & 3.01 & 0 & 14 & 1.63 & 2.79 & 0 & 10 & 0.9433 \\
\hline Social worker & 1.35 & 2.55 & 0 & 12 & 1.21 & 1.96 & 0 & 6 & 0.7834 \\
\hline Dietician & 0.32 & 1.58 & 0 & 13 & 0.79 & 2.07 & 0 & 7 & 0.3612 \\
\hline Home caregivers & 1.06 & 3.97 & 0 & 24 & 0.00 & 0.00 & 0 & 0 & 0.0074 \\
\hline Informal caregivers & 1.47 & 5.24 & 0 & 25 & 0.21 & 0.63 & 0 & 2 & 0.0198 \\
\hline Other specialists & 2.04 & 3.41 & 0 & 18 & 2.89 & 3.09 & 0 & 11 & 0.2838 \\
\hline Other caregivers & 3.02 & 4.33 & 0 & 24 & 1.84 & 3.29 & 0 & 12 & 0.1833 \\
\hline \multicolumn{10}{|l|}{ Care duration (minutes) } \\
\hline General practitioner & 43.51 & 77.58 & 0 & 580 & 51.63 & 64.36 & 0 & 201 & 0.6285 \\
\hline Physiotherapist & 761.59 & $\mathrm{I}, \mathrm{I} 10.93$ & 0 & 6,480 & 775.37 & I,04I.24 & 0 & 3,560 & 0.9585 \\
\hline Occupation therapist & 95.76 & 198.66 & 0 & $\mathrm{I}, 020$ & 101.84 & 208.21 & 0 & 795 & $0.907 \mid$ \\
\hline Social worker & 81.95 & 168.34 & 0 & 1,050 & 67.63 & 111.15 & 0 & 320 & 0.6398 \\
\hline Dietician & 12.35 & 69.19 & 0 & 662 & 21.84 & 54.95 & 0 & 200 & 0.5122 \\
\hline Home caregivers & 211.90 & 795.47 & 0 & 4,785 & 0.00 & 0.00 & 0 & 0 & 0.0074 \\
\hline Informal caregivers & 472.84 & $2,126.78$ & 0 & 15,275 & 19.26 & 82.52 & 0 & 360 & 0.0318 \\
\hline Other specialists & 127.52 & 275.20 & 0 & $\mathrm{I}, 870$ & 216.05 & 282.88 & 0 & 975 & 0.2193 \\
\hline Other caregivers & 225.63 & 761.18 & 0 & 7,150 & 124.05 & 254.01 & 0 & 865 & 0.2850 \\
\hline
\end{tabular}

2.20 , respectively) ( $P=0.0349, P=0.0064, P=0.0091$, and $P=0.0180$, respectively). The home care duration (minutes) in the adherent group ranged from 7 (mean) (SD 34.20, minimum 0, maximum 220) in Q1 to 25 (mean) (SD 117, minimum 0, maximum 780) in Q4 $(P=0.0409, P=0.0064$, $P=0.0139$, and $P=0.0294$, respectively). Similarly, the informal care frequencies in the first three quarters were significantly higher in adherent patients than in nonadherent patients (mean values 0.10 vs 0.02 [ $P=0.0302], 0.11$ vs $0.02[P=0.0329]$, and 0.13 vs $0.00[P=0.0078]$ ), as were the informal care durations (minutes) in all four quarters (mean values 30.55 vs 0.04 [ $P=0.0409]$, 43.65 vs 0.07 [ $P=0.0064]$, 40.92 vs $0.00[P=0.0130]$, and 40.92 vs $6.32[P=0.0294])$.

\section{Discussion}

In MS patients in their first year of treatment with GA $20 \mathrm{mg}$ sc daily, we first observed that those who discontinued treatment in Q4 had less-frequent and shorter psychological care in Q3, whereas no association was found between discontinuation and neurological, nursing, pharmaceutical, and rehabilitative care in either quarter; second, no relationship was observed between the frequency or duration of neurological, nursing, psychological, pharmaceutical, or rehabilitative care and adherence; and third, an association between the frequency and duration of home care and informal care and adherence was observed during explorative analyses.
According to the World Health Organization, adherence is "the extent to which a person's behaviour - taking medication, following a diet, and/or executing lifestyle changes-corresponds with agreed recommendations from a health care provider". ${ }^{6}$ Given that drug treatments in chronic disorders are only optimally effective in the long term and with virtually no missed doses, the notion "adherence" has the following two aspects: the persistence of treatment (no discontinuation) and the application of the agreed dosing scheme (no missed doses). With respect to disease-modifying treatment in MS, however, the term adherence is also being used to specifically describe persistence, ${ }^{16}$ which may be confusing. We choose to use adherence in a strict sense, ie, adherence to dosing as agreed. ${ }^{17}$ This is in-line with adherence as defined by the International Society for Pharmacoeconomics and Outcomes Research Medication Compliance and Persistence Special Interest Group: "adherence is the percentage of doses taken as prescribed, over a set time period for analysis (either from the first to last medication dispensing date or for a fixed follow-up time frame)". ${ }^{18}$

The 12-month persistence rate was $62 \%$. In a comparable study, we observed a 12-month persistence of treatment with GA $20 \mathrm{mg}$ sc daily of $71.6 \%{ }^{2}$ In an open-label observational study on a German cohort of 308 MS patients, GA's persistence rates at 6 months and 24 months of observation were $91.1 \%$ and $67.1 \%$, respectively. ${ }^{19}$ 
We observed that patients who discontinued treatment in Q4 had received less-frequent and shorter psychological care in Q3. Psychological problems, such as depression and anxiety, occur frequently in $\mathrm{RRMS}^{20}$ and are known to negatively affect adherence. ${ }^{21}$ It is conceivable that, in Q3, the effectiveness of the new treatment is provisionally evaluated. Supposedly, in depressed or anxious patients, eventual doubts about effectiveness may lead more often to treatment discontinuation than in patients without these symptoms. In this context, the identification of depressed and anxious patients and their timely psychological treatment, therefore, may be thought to prevent discontinuation on improper grounds, especially after Q3.

The percentage of missed doses was low in our study, as $84.7 \%$ of the persistent patients had reportedly injected at least $95 \%$ of the prescribed doses and $99 \%$ of the patients at least $85 \%$ of the doses. This high adherence may result from study-related factors. First, the self-report method may overestimate adherence. Second, as patients were asked to report twelve times over a 1 -year period, the number of doses they had missed in the preceding 2 weeks, the study participation will have led to an increased awareness in patients of adherence, helping them to not forget their injections. It has been known that "forgot to inject" is one of the main reasons for missing doses. ${ }^{21,22}$ Importantly, however, high adherence has also been reported in INF $\beta$-1a-treated patients who used an autoinjector with electronic registration of injections: the mean (SD) cumulative adherence until the 12th month or treatment discontinuation was $97.1 \% \pm 7.3 \% .{ }^{22}$ Therefore, we hypothesize that, in our patients, an increased awareness, resulting from the frequent reporting of injected doses, is more likely to have caused the high adherence figure than the self-report method. Although our study suggests that frequent online self-reports on missed doses might improve adherence, we think that, in real life, this approach is not effective as the attrition rate, both in terms of discontinuation and nonadherence to the online reporting scheme, is expectedly high.

The $80 \%$ cutoff is frequently used to define adequate adherence, also in MS. ${ }^{23}$ Yet it deserves to be questioned, as it means that one out of five doses is not taken. Given that a recent 15 -year follow-up study of a randomized controlled trial suggests that higher cumulative exposure to sc IFN $\beta-1 \mathrm{a}$ may be associated with better clinical outcomes, ${ }^{8}$ the missing of $20 \%$ of the doses is likely to be clinically relevant. Therefore, we propose to use $90 \%$ or $95 \%$ cutoff for determining adequate adherence, in agreement with Treadaway et al, ${ }^{21}$ whose definition of nonadherence (missing any injection within the last 4 weeks) implies $92 \%, 93 \%$, and $96 \%$ thresholds for sc INF- $\beta-1 \mathrm{a}$, INF- $\beta-1 \mathrm{~b}$, and daily GA, respectively.

We obtained no evidence for associations between adherence and the frequency or duration of care given by neurologists, nurses, psychologists, pharmacists, or rehabilitation doctors. In the explorative analyses, we found associations between home care and adherence and between informal care and adherence. We first assumed that patients who were not capable to self-inject due to motor, sensory, visual, or coordinative disabilities (as well as patients with a needle phobia or self-injection anxiety, well-known barriers to proper adherence to GA) had the injections administered by home care or informal caregivers. ${ }^{24}$ However, as the highest home care frequency reported was 24 (in 12 months) (mean 10.1, SD 8.0, median 10) and the highest informal care frequency reported was 25 (mean 8.8, SD 10.0, median 2.0), it is unlikely that the administration of injections explains the association with adherence. In addition, recent reports show that home care and informal care may otherwise improve adherence. The mere presence of a caregiver at home significantly improved medication adherence in older individuals with heart failure and mild cognitive impairment; ${ }^{25}$ about one-third of RRMS patients show cognitive impairment, including memory disturbances. ${ }^{20}$ In an uncontrolled study on the effectiveness of a community-based weight reduction program, participants were requested to identify three family members and friends to sign a social support contract; independent risk factors for not completing the program were not having a family member or friend to sign a social support contract. ${ }^{26}$ In MS, it has been found that, in contrast to nonadherent patients, patients who were highly adherent perceived greater support from their spouse ${ }^{21}$ and pilot data suggest that telephone counseling and home telehealth monitoring may improve adherence. ${ }^{27}$ In all, the effect of home care and informal care on adherence in MS patients, as suggested by our data, is most likely mediated via social processes.

Our study has several limitations. In view of the high adherence in our patients, it cannot be taken for granted that the findings apply to populations with lower adherence. Also, the geographical setting of the study (one country in Western Europe) and the relatively high overall quality of the health care $^{28}$ warrant a careful extrapolation of the results to other societies or countries with different health care systems. Perhaps most important, we did not assess the quality of the care that was delivered, and it may well be that associations do exist between the knowledge, expertise, experience, or communicative skills of caregivers and persistence and adherence. 


\section{Conclusion}

In MS patients in their first year of treatment with GA $20 \mathrm{mg}$ sc daily, we observed a $62 \%$ persistence rate with $85 \%$ of persistent patients being $95 \%$ adherent. Patients who stopped treatment in Q4 had received less-frequent and shorter psychological care in Q3, whereas there were no associations between discontinuation and neurological, nursing, pharmaceutical, and rehabilitative cares in either quarter. No relationship was found between the frequency or duration of neurological, nursing, psychological, pharmaceutical, or rehabilitative care and adherence. Explorative analyses suggest an association between the frequency and duration of home care and informal care and adherence.

\section{Acknowledgments}

We thank the neurologists and nurses who provided the study information to their patients, the neurologists H Jacobus Gilhuis (Reinier de Graaf Gasthuis, Delft, the Netherlands), Theodora Siepman (Erasmus Medical Centre, Rotterdam, the Netherlands), Erik van Munster (Jeroen Bosch Hospital, Den Bosch, the Netherlands), Ruud van der Kruijk (Slingeland Hospital, Doetinchem, the Netherlands), Angelique Schyns-Soeterboek (Laurentius Hospital, Roermond, the Netherlands), Pieter Bernsen (St Jansdal Hospital, Harderwijk, the Netherlands), and Ron Witjes (Tergooi Hospital, Hilversum, the Netherlands) for providing neurological data and Anton Kool (Curavista BV, Geertruidenberg, the Netherlands) for providing technical support. We are grateful to TEVA Netherlands for financial support via an independent and unrestricted research grant. TEVA Netherlands had the opportunity to review the final version of the article to address any factual inaccuracies or request the redaction of information deemed to be proprietary or confidential and ensure that study support was disclosed.

\section{Disclosure}

Peter Joseph Jongen has received honoraria from Allergan, Bayer, Merck and Teva for contributions to symposia as a speaker or for consultancy activities. Esther van Noort is coowner of Curavista bv. The other authors report no conflicts of interest in this work.

\section{References}

1. Freedman MS. Disease-modifying drugs for multiple sclerosis: current and future aspects. Expert Opin Pharmacother. 2006;7(suppl 1): S1-S9.

2. Jongen PJ, Lehnick D, Sanders E, et al; FOCUS study group. Health-related quality of life in relapsing remitting multiple sclerosis patients during treatment with glatiramer acetate: a prospective, observational, international, multi-centre study. Health Qual Life Outcomes. 2010;8:133.
3. Jongen PJ, Sindic C, Carton H, et al; Functional composite and quality of Life in Avonex-treated Relapsing multiple sclerosis patients study group. Improvement of health-related quality of life in relapsing remitting multiple sclerosis patients after 2 years of treatment with intramuscular interferon-beta-1a. J Neurol. 2010;257(4):584-589.

4. Trojano M, Pellegrini F, Paolicelli D, et al; Italian Multiple Sclerosis Database Network (MSDN) Group. Real-life impact of early interferon beta therapy in relapsing multiple sclerosis. Ann Neurol. 2009; 66(4):513-520.

5. Vermeire E, Hearnshaw H, Van Royen P, Denekens J. Patient adherence to treatment: three decades of research. A comprehensive review. J Clin Pharm Ther. 2001;26(5):331-342.

6. World Health Organization. Adherence to Long-term Therapies: Evidence for Action. Geneva: World Health Organization; 2003.

7. Uitdehaag B, Constantinescu C, Cornelisse P, et al. Impact of exposure to interferon beta-1a on outcomes in patients with relapsing-remitting multiple sclerosis: exploratory analyses from the PRISMS long-term follow-up study. Ther Adv Neurol Disord. 2011;4(1):3-14.

8. Kappos L, Kuhle J, Multanen J, et al. Factors influencing long-term outcomes in relapsing-remitting multiple sclerosis: PRISMS-15. J Neurol Neurosurg Psychiatry. 2015;86(11):1202-1207.

9. Steinberg SC, Faris RJ, Chang CF, Chan A, Tankersley MA. Impact of adherence to interferons in the treatment of multiple sclerosis: a nonexperimental, retrospective, cohort study. Clin Drug Investig. 2010; 30(2):89-100

10. Ivanova JI, Bergman RE, Birnbaum HG, Phillips AL, Stewart M, Meletiche DM. Impact of medication adherence to disease-modifying drugs on severe relapse, and direct and indirect costs among employees with multiple sclerosis in the US. J Med Econ. 2012;15(3): 601-609.

11. Lafata JE, Cerghet M, Dobie E, et al. Measuring adherence and persistence to disease-modifying agents among patients with relapsing remitting multiple sclerosis. J Am Pharm Assoc (2003). 2008;48(6): $752-757$.

12. Moccia M, Palladino R, Russo C, et al. How many injections did you miss last month? A simple question to predict interferon beta-1a adherence in multiple sclerosis. Expert Opin Drug Deliv. 2015;12(12):1829-1835.

13. Jongen PJ, Hengstman G, Hupperts R, et al. Drug adherence and multidisciplinary care in patients with multiple sclerosis: protocol of a prospective, web-based, patient-centred, nation-wide, Dutch cohort study in glatiramer acetate treated patients (CAIR study). BMC Neurol. 2011;11:40.

14. Sport MoHWa. Dutch medical research involving human subjects act (WMO). Available from: http://wetten.overheid.nl/BWBR0009408/201512-17. Accessed April 29, 2016. Dutch.

15. Summary of product characteristics. Copaxone ${ }^{\circledR} 20 \mathrm{mg} / \mathrm{ml}$ Solution for Injection, Pre-filled Syringe. Available from: http://www.tevauk.com/ mediafile/id/15860.pdf. Accessed April 29, 2016.

16. Giovannoni G, Southam E, Waubant E. Systematic review of diseasemodifying therapies to assess unmet needs in multiple sclerosis: tolerability and adherence. Mult Scler. 2012;18(7):932-946.

17. Bergvall N, Petrilla AA, Karkare SU, et al. Persistence with and adherence to fingolimod compared with other disease-modifying therapies for the treatment of multiple sclerosis: a retrospective US claims database analysis. J Med Econ. 2014;17(10):696-707.

18. Cramer JA, Roy A, Burrell A, et al. Medication compliance and persistence: terminology and definitions. Value Health. 2008;11(1): 44-47.

19. Haas J, Firzlaff M. Twenty-four-month comparison of immunomodulatory treatments - a retrospective open label study in 308 RRMS patients treated with beta interferons or glatiramer acetate (Copaxone). Eur J Neurol. 2005;12(6):425-431.

20. Langdon DW. Cognition in multiple sclerosis. Curr Opin Neurol. 2011; 24(3):244-249.

21. Treadaway K, Cutter G, Salter A, et al. Factors that influence adherence with disease-modifying therapy in MS. J Neurol. 2009;256(4): $568-576$. 
22. Bayas A, Ouallet JC, Kallmann B, et al; SMART study group. Adherence to, and effectiveness of, subcutaneous interferon beta-1a administered by RebiSmart(R) in patients with relapsing multiple sclerosis: results of the 1-year, observational SMART study. Expert Opin Drug Deliv. 2015;12(8):1239-1250.

23. Reynolds MW, Stephen R, Seaman C, Rajagopalan K. Persistence and adherence to disease modifying drugs among patients with multiple sclerosis. Curr Med Res Opin. 2010;26(3):663-674.

24. Costello K, Kennedy P, Scanzillo J. Recognizing nonadherence in patients with multiple sclerosis and maintaining treatment adherence in the long term. Medscape J Med. 2008;10(9):225.

25. Foebel AD, Hirdes JP, Heckman GA. Caregiver status affects medication adherence among older home care clients with heart failure. Aging Clin Exp Res. 2012;24(6):718-721.
26. Lemstra M, Rogers MR. The importance of community consultation and social support in adhering to an obesity reduction program: results from the healthy weights initiative. Patient Prefer Adherence. 2015; 9:1473-1480.

27. Turner AP, Sloan AP, Kivlahan DR, Haselkorn JK. Telephone counseling and home telehealth monitoring to improve medication adherence: results of a pilot trial among individuals with multiple sclerosis. Rehabil Psychol. 2014;59(2):136-146.

28. van den Berg MJ, Kringos DS, Marks LK, Klazinga NS. The Dutch Health Care Performance Report: seven years of health care performance assessment in the Netherlands. Health Res Policy Syst. 2014;12:1.

\section{Publish your work in this journal}

Patient Preference and Adherence is an international, peer-reviewed, open access journal that focuses on the growing importance of patient preference and adherence throughout the therapeutic continuum. Patient satisfaction, acceptability, quality of life, compliance, persistence and their role in developing new therapeutic modalities and compounds to optimize clinical outcomes for existing disease states are major areas of interest for the journal. This journal has been accepted for indexing on PubMed Central. The manuscript management system is completely online and includes a very quick and fair peer-review system, which is all easy to use. Visit http://www. dovepress.com/testimonials.php to read real quotes from published authors.

\footnotetext{
Submit your manuscript here: http://www.dovepress.com/patient-preference-and-adherence-journal
} 